\title{
Sistema de Gestão de Qualidade aplicado ao Jornalismo: possibilidades e diretrizes ${ }^{1}$
}

\author{
Josenildo Guerra
}

\section{Resumo}

0 artigo reflete sobre as possibilidades de

desenvolvimento de um sistema de gestão e avaliação de qualidade para organizações jornalísticas. Analisa dificuldades, como ausência de métodos objetivos para aferição das características dos produtos e a falta de consenso acerca dos valores e requisitos desejáveis. E aponta desafios: construir métodos confiáveis, obter valores consensuais e gerar inovação para produtos e processos decorrentes das avaliações realizadas. Define um conceito de qualidade e propõe dois requisitos básicos, verdade e relevância. Conclui com a apresentação de uma proposta preliminar de sistema de gestão da qualidade assentada em três partes: a) compromissos e estrutura organizacional; b) processos de produção; e c) produtos.

\section{Palavras-chave:}

Jornalismo. Qualidade. Inovação.

\section{Josenildo Guerra I jguerra@ufs.br}

Doutor em Comunicação e Cultura Contemporâneas pela Universidade Federal da Bahia - UFBA. Professor da Universidade Federal de Sergipe.

\section{Introdução}

0 compromisso com a qualidade figura como central em discursos de várias organizações, jornalísticas ou não. Segundo Slack, Chambers e Johnston (2007, p. 549), "jornais de negócios e revistas de gerenciamento são dominados por artigos sobre qualidade. Parece que temos vivido uma 'revolução de qualidade"'. A causa para tanta atenção decorre, segundo os autores, de uma crescente consciência de que

[...] bens e serviços de alta qualidade podem dar a uma organização uma considerável vantagem competitiva. Boa qualidade reduz custos de retrabalho, refugo e devoluções e, mais importante, boa qualidade gera consumidores satisfeitos. Alguns gerentes de produção acreditam que, a longo prazo, a qualidade é o mais importante fator singular que afeta o desempenho de uma organização em relação as seus concorrentes (SLACK; CHAMBERS; JOHNSTON, 2007, p. 549).

A qualidade é um recurso organizacional de vinculação entre a esfera da produção de bens e serviços e a esfera do consumo desses bens e serviços. Em relação aos produtores, a incorporação efetiva da gestão da qualidade e sua 
implementação trazem vantagens competitivas para a organização, que podem colocá-la na liderança do segmento em que atua. 0 retorno pretendido pode vir na melhoria da imagem organizacional projetada publicamente e, em consequência, no aumento dos lucros decorrentes da condição alcançada.

Em relação à esfera do consumo, a indicação de qualidade - por meio de dispositivos de certificação existentes para tal, da experiência vivida pelo próprio consumidor ou por pessoas do seu círculo de convivência - representa uma segurança de que o produto oferecido contém efetivamente as características e a funcionalidade pretendidas pelo cliente. Confere segurança na relação de consumo, em virtude da credibilidade que o rótulo "qualidade" conquista junto aos consumidores.

No âmbito do negócio jornalístico, tanto as organizações buscam sinalizar seu compromisso com a qualidade quanto a sociedade busca organizar-se, a seu modo e de diferentes formas, a fim de cobrar o melhor dos produtos que recebe ${ }^{2}$.
0 problema é que nem sempre, ou quase sempre, a reivindicação de qualidade ou o seu contrário vem acompanhada de meios seguros de aferição. 0 produto "é de qualidade" porque quem 0 oferece diz que é. Ou o produto "não é de qualidade" porque algum crítico diz que não. Assim, o discurso da qualidade ou da sua ausência no âmbito da produção jornalística acaba por apresentar duas sérias limitações: a) nem sempre é suficientemente demonstrado, com dados de aferição obtidos por métodos claros e confiáveis; b) em consequência, nem sempre é reconhecido objetivamente pelos demais atores da área como válido.

Essas duas limitações nos remetem a três desafios que podemos identificar junto à comunidade científica de pesquisadores em jornalismo, aos gestores organizacionais, aos profissionais dos meios de comunicação e à sociedade: a) desenvolver métodos claros e confiáveis para a avaliação de desempenho do trabalho e de qualidade dos produtos jornalísticos; b) obter parâmetros consensuais acerca das melhores práticas e dos valores que devem reger o negócio; c) produzir pesquisas

Este trabalho apresenta resultados preliminares de duas pesquisas: 1) gestão da produção jornalística, com apoio do Conselho Nacional de Desenvolvimento Científico e Tecnológico (CNPq), agência brasileira de fomento à pesquisa; 2) IQJ - indicadores de qualidade jornalística, produzida no contexto da cooperação UNESC0 / Rede Nacional de Observatórios da Imprensa (projeto 4513103037BRZ - As opiniões nele expressas são de responsabilidade do autor e não refletem necessariamente a visão da UNESCO sobre 0 assunto). Versão preliminar deste artigo, Notas sobre 0 desenvolvimento de pesquisa de avaliação de qualidade aplicada ao Jornalismo foi apresentada no GP Teoria do Jornalismo, IX Encontro dos Grupos/Núcleos de Pesquisas em Comunicação, evento componente do XXXII Congresso Brasileiro de Ciências da Comunicação, realizado em 2009, em Curitiba (PR).

Como exemplo, pode-se mencionar os chamados Sistemas de Responsabilização de Mídia (MAS), conforme denominados por Claude-Jean Bertrand. Podem ser considerados MAS "quaisquer meios de melhorar os serviços de mídia ao público, totalmente independentes do governo. [...] São um misto de controle de qualidade, serviço ao consumidor, educação contínua e muito mais não apenas, decerto, auto-regulamentação" (BERTRAND, 2002, p. 35). 
geradoras de inovação tanto de métodos de avaliação quanto de produção jornalística, capazes de atender a exigências cada vez maiores - espera-se - de qualidade (medida e verificada) para produtos jornalísticos.

A incorporação de estudos e de sistemas de gestão de qualidade - fortemente disseminados e exitosos em outros ramos de negócio - ao jornalismo pode ser um fator decisivo para desencadear uma consciência acadêmica, profissional e cidadã que nos faça enfrentar os desafios acima assinalados.

\section{Algumas experiências de avaliação de qualidade em jornalismo}

A discussão sobre a qualidade na atividade jornalística ainda é incipiente quando considerada à luz das ferramentas de gestão, avaliação e certificação de qualidade. Dos poucos trabalhos existentes, a maior parte aborda a questão de forma indireta (PINTO; MARINHO, 2003, p. 4) 3. Além disso, é possível constatar uma maior ocorrência de experiências de avaliação de qualidade do que uma discussão acadêmico-científica sobre o tema, o que sugere existir nessa área específica o mesmo que acontece mais genericamente no campo do jornalismo e da comunicação: uma apartação entre a esfera da produção técnica e a esfera da produção científica ${ }^{4}$. Esse se constitui, aliás, em um grave problema na área de comunicação e especificamente do jornalismo, o que resulta em uma quase inexistente atividade de pesquisa e desenvolvimento de produtos e processos, consequentemente, de inovação resultante de trabalhos científicos.

Algumas experiências internacionais têm contribuído com modelos e parâmetros para se avaliar o compromisso com a qualidade de organizações jornalísticas. No Brasil, a incorporação de metodologias voltadas à medição e à atribuição de critérios objetivos de aferição ainda não gerou ferramentas que pudessem ser disponibilizadas publicamente para processos de avaliação.

Uma das experiências mais avançadas que temos por aqui, se não a mais avançada até o momento, é a da Agência de Notícias dos Direitos da Infância (Andi). Desde 1996, a Andi faz o monitoramento da cobertura da infância e adolescência nos jornais brasileiros. Fruto do aperfeiçoamento de sua metodologia, desenvolveu um ranking quanti-qualitivativo dos jornais monitorados, por meio do cálculo de

Eles identificaram basicamente três polos de interesse nos artigos pesquisados: a) a qualidade como uma característica da organização e do produto; b) a qualidade entendida enquanto serviço público; c) a qualidade vista como um investimento estratégico.

Embora o termo seja forte, "apartação", o que se afirma é a inexistência de uma tradição consolidada de pesquisa aplicada para o desenvolvimento de produtos e de práticas em nossa área. Há o predomínio de pesquisas essencialmente teóricas ou de diagnóstico (analíticas ou descritivas sobre conteúdos e práticas). Para uma análise mais detida sobre isso no âmbito do jornalismo, especificamente, ver Meditsch (1999). 
um índice resultante da média ponderada de 18 itens, os quais receberam pesos diferenciados de acordo com a relevância considerada para os temas avaliados (AGÊNCIA DE NOTÍCIAS DOS DIREITOS DA INFÂNCIA, 2005, p. 8-16).

Duas experiências internacionais relevantes podem sugerir algumas tendências que vêm surgindo. Uma é a da Fundación Prensa y Democracia México (Fundación Prende). A partir de ampla pesquisa internacional, da leitura do cenário comunicacional mexicano e da afirmação categórica de que a democracia exige informação de qualidade para o melhor exercício da cidadania, elaborou-se um conjunto de oito princípios, a saber: a) transparência nos processos de construção e processamento da informação; b) verificação e contextualização dos dados e informações; c) investigação jornalística; d) espaços de comunicação horizontal entre jornalistas, editores e diretores; e) códigos de ética; f) mecanismos de contrapeso aos meios: direito de resposta, defensoria do leitor, ouvidoria e observatórios civis; g) igualdade na distribuição de verba publicitária; e h) direito e acesso à informação. 0 documento relata três níveis de consideração desses princípios: uma descrição inicial do item; na sequência, propõe linhas de ação a serem seguidas; e, finalmente, sugere indicadores concretos a partir dos quais se possam avaliar os resultados atingidos.

A outra experiência é fruto da parceria entre a International Standartization \& Accreditation
Services (Isas) e a Media \& Society Foundation (MSF). A primeira é uma organização privada voltada para a certificação e acreditação de serviços, cuja missão é assessorar instituições privadas, públicas e governamentais que buscam estabelecer e manter padrões de qualidade em prol do interesse público, e acreditar grupos de certificação para verificar o compromisso com tais padrões. A segunda é uma organização suíça sem fins lucrativos, que tem como missão estimular o desenvolvimento de padrões de qualidade para organizações de comunicação. No seu instrumento de avaliação para a indústria da comunicação, especificamente, do setor jornalístico, foram identificados treze critérios: a) qualidade da informação; b) qualidade do conteúdo; c) ética; d) independência; e) relacionamento com anunciantes; f) relacionamento com o público; g) relacionamento com autoridades públicas; h) transparência; i) pesquisa de audiência; j) gerenciamento de recursos humanos; k) organização do trabalho; l) infra-estrutura; e m) relacionamento com fornecedores.

Tais exemplos apontam para uma tendência de avaliação e gestão da qualidade para organizações jornalísticas. 0 objetivo deste artigo, sob inspiração de tais referências, é sistematizar um esboço inicial de sistema de gestão de qualidade aplicado a organizações jornalísticas, composto por três conjuntos de requisitos: a) compromissos e estrutura organizacional; b) processos de produção; e c) produtos. 
Antes disso, porém, vamos nos ater a uma definição inicial de qualidade.

\section{Qualidade e desempenho para organizações jornalísticas}

Na literatura da área de administração, qualidade pode ser definida a partir de dois aspectos: a adequação a padrões previamente definidos (denominados especificações) pela própria organização (CHIAVENATO, 2007, p. 374-375) e 0 "grau de adequação entre as expectativas dos consumidores e a percepção deles do produto ou serviço" (BERRY; PARASURAMAN apud SLACK; CHAMBERS; JOHNSTON, 2007, p. 552-553) ${ }^{5}$ . 0 primeiro aspecto diz respeito à qualidade interna, o segundo, à qualidade externa. "Não resta dúvida de que, sem a qualidade interna não se pode construir e manter a imagem da qualidade externa" (CHIAVENATO, 2007, p. 375). 0 mesmo se pode dizer do contrário: sem atentar para os requisitos da qualidade externa, uma organização jamais poderá definir padrões internos satisfatórios.

Segundo a norma ABNT NBR IS0 9000:2005, qualidade é 0 "grau no qual um conjunto de características inerentes satisfaz a requisitos", sendo requisito a "necessidade ou expectativa [em relação a um produto ou serviço] que é expressa, geralmente, de forma implícita ou explícita". Entre essas três definições, podemos propor uma síntese do conceito de qualidade como uma comparação entre características apresentadas pelos produtos e os requisitos: a) necessários para o seu funcionamento; e b) esperados pelos usuários. Quanto mais próximas as características estiverem dos requisitos, maior a qualidade.

Mas, no jornalismo, quais seriam os requisitos de qualidade para seus produtos? No âmbito da atividade jornalística, são duas as expectativas básicas da audiência em relação à notícia: verdade e relevância. Verdade porque se espera que a notícia ponha a audiência a par de fatos reais ${ }^{6}$. Relevância porque não são todos os fatos reais que têm valor jornalístico, mas aqueles que atendam à demanda da audiência ? .

Aqui enfrentamos uma primeira dificuldade para tratar o tema: justificar tais parâmetros como sendo de qualidade e fundamentá-los, cientificamente. Esses são passos importantes, pois quando 0 assunto é qualidade e sistemas de avaliação de qualidade, está pressuposta

5 Essa definição representa uma síntese. Os autores buscaram sintetizar e conciliar as diferentes visões sobre a qualidade: a abordagem transcendental, a baseada na manufatura, a baseada no usuário, a baseada no produto e a baseada no valor (SLACK; CHAMBERS; JOHNSTON, 2007, p. 550-551). Outro tipo de classificação proposta faz referência a cinco abordagens: transcendental, baseada no produto, baseada no usuário, baseada na produção e baseada no valor (CARVALH0, 2005, p. 8-9).

Segundo Gomes, "um fato [...] é um complexo que inclui eventos envolvendo coisas, pessoas e textos. As suas marcas características são a atividade, a relação e a temporalidade. [...] 0 fato é o resultado, a consequência de uma ação, aquilo que uma produção ou operação deixa para trás como seu produto ou sua obra" (GOMES, 2009, p. 30).

A afirmação da verdade e da relevância como parâmetros de qualidade é baseada em Guerra (2008). 
uma forte dose de consenso. Tanto que uma das premissas básicas para a discussão e 0 desenvolvimento de ferramentas desse tipo é 0 amplo acordo entre as diferentes partes envolvidas e interessadas na construção das referências. No caso da norma ABNT NBR ISO 9000, por exemplo:

As Normas Brasileiras, cujo conteúdo é de responsabilidade dos Comitês Brasileiros (ABNT/ CB), dos Organismos de Normalização Setorial (ABNT/NOS) e das Comissões de Estudo Especiais Temporárias (ABNT/CEET), são elaboradas por Comissões de Estudo (CE), formadas por representantes dos setores envolvidos, delas fazendo parte: produtores, consumidores e neutros (universidades, laboratórios e outros).

\begin{abstract}
A ABNT NBR ISO 9000 foi elaborada no Comitê Brasileiro da Qualidade (ABNT/CB-25), pela Comissão de Estudo de Fundamentos e Vocabulário (CE-25:001.01). 0 Projeto circulou em Consulta Nacional conforme Edital Especial de 07.12.2000, com 0 número de Projeto ABNT NBR ISO 9000. Seu Projeto de Emenda 1 circulou em Consulta Nacional conforme Edital no. 10, de 31.10.2005 (ASSOCIAÇÃO BRASILEIRA DE NORMAS TÉCNICAS, 2005, p. iv).
\end{abstract}

Fortes consensos, convém admitir, não estão entre as maiores virtudes da área de comunicação e de jornalismo. Em consequência, torna-se impossível a pretensão de dar conta da dificuldade mencionada acima neste artigo.

A justificativa da verdade e da relevância como parâmetros enseja um debate ético-político que, embora muito caro às democracias ocidentais, especialmente a partir do século XVII, esbarra em fortes críticas sobretudo no ambiente acadêmico da área de comunicação e do jornalismo. A sua fundamentação científica, por sua vez, é ainda mais duramente questionada: muitas correntes não reconhecem a verdade como possibilidade gnosiológica, e a relevância é praticamente um tema inexplorado ${ }^{8}$.

Feito tal registro, a decisão de considerar a verdade e a relevância como parâmetros de qualidade implica aceitar o modelo de jornalismo profissional desenvolvimento pela tradição das sociedades democráticas ocidentais, especialmente gestado nos Estados Unidos e na Inglaterra (FRANCISCATO, 2005; CHALABY; 1998). Não são ignoradas nem desqualificadas as teses críticas, entretanto. Elas são reconhecidas e convidadas a assumir a parte que lhes cabe no problema aqui proposto: oferecer parâmetros e métodos para avaliação de produtos e processos jornalísticos. De nossa parte, é a isso que nos propomos neste artigo, com base no modelo aqui definido.

A expectativa de verdade requer uma base factual para a informação. A sociedade espera que as notícias tratem de fatos, por isso a invenção, a distorção e a mentira são consideradas faltas graves para o jornalista. As informações contidas nas notícias devem ser suportadas por provas de veracidade, como documentos, testemunhos e registros (imagéticos ou sonoros). E o jornalista, 
ao obter as informações, precisa ter feito uso

de métodos confiáveis como entrevistas com fontes seguras, observação direta e pesquisa documental. Os profissionais não são obrigados a revelar seus métodos na notícia, em função do tempo e da brevidade do relato, mas em tese devem tê-los documentados e disponíveis para verificação pública, se necessário for.

A expectativa de relevância no jornalismo recebe 0 nome técnico de valor-notícia ${ }^{9}$. Esses funcionam como idealizações do espectador real, a partir das quais os jornalistas podem prever qual é o seu interlocutor e qual a sua demanda de informações ${ }^{\text {t0 }}$. Quando os valores-notícia são definidos a partir das expectativas de uma particular audiência, porque sistematizados por uma organização jornalística que visa esta audiência, tem-se os Valores-Notícia de Referência ${ }^{11}$. Eles resultam das expectativas da audiência incorporadas pela organização, a partir das quais esta processa uma série de definições até chegar ao melhor ponto de ajuste entre aquelas expectativas e a sua capacidade de produzir notícias.

Os valores-notícia podem ser de duas ordens. São de ordem privada quando definidos por demandas específicas de grupos de indivíduos, relativas a gostos e preferências particulares. Nesse sentido, variam de audiência para audiência. Por isso, cada organização pode operar com um conjunto próprio de valores-notícia em função da audiência a que visa. São de ordem pública quando o assunto em pauta se constitui objeto de interesse público. Nas sociedades democráticas, o jornalismo é uma atividade das mais solicitadas para prover o direito à informação da sociedade. Em virtude disso, o interesse público se apresenta como um Valor-Notícia de Referência Universal.

Considerar os valores-notícia como expectativas da audiência e, consequentemente, utilizá-los

A consideração de valor-notícia como tipificação das expectativas de relevância da audiência é feita por Guerra (2008). Nesse trabalho, no qual se baseia toda a discussão sobre verdade e relevância do presente artigo, sustenta-se que são tais expectativas de relevância que justificam, fundamentam e geram os valores-notícia. Tal ponto de vista procura ir além da abordagem descritiva presente nos estudos do newsmaking, a partir de uma perspectiva fortemente organizacional, a fim de permitir justamente a avaliação dos valores-notícia usados para selecionar ou excluir fatos e notícias.

10

Os valores-notícia funcionariam para os jornalistas desenhando o perfil do seu "leitor-modelo" ou do seu "leitor-imaginário". Segundo Eco, "o texto postula a cooperação do leitor como condição própria de atualização. Podemos dizer melhor que o texto é um produto cujo destino interpretativo deve fazer parte do próprio mecanismo gerativo. Gerar um texto significa executar uma estratégia de que fazem parte as previsões dos movimentos de outros - como, aliás, em qualquer estratégia" (EC0,2002, p. 39). No entanto, acrescenta, "prever o próprio Leitor-Modelo não significa somente 'esperar' que exista, mas significa também mover 0 texto de modo a construí-Io. 0 texto não apenas repousa numa competência, mas contribui para reproduzi-la”(op. cit., p. 40). E leitor imaginário: "Early reserch into the communicator-audience relationship drew on the theory of Herbert Mead (1934) and, before him, Charles Cooley (1908), especially by picking up the idea of an 'imaginary interlocutor'. The essence of the theory is that in order to communicate we need to have some known 'reference person' or group to whom we can address ourselves, as well as having a shared cultural and social space and a common language" (MCQUAIL, 1997, p. 112).

Os Valores-Notícia de Referência são os efetivamente usados pelas organizações. Mas, há também os Valores-notícia Potenciais, que representam as expectativas presentes na sociedade e em audiências também potenciais que ainda não foram incorporados pelas organizações. Nos Valores-Notícia Potenciais repousam oportunidades de inovação de conteúdo para 0 jornalismo (GUERRA, 2008). 
como parâmetros de qualidade para avaliação da relevância jornalística das notícias exigem levar em conta essas duas ordens.

Ao afirmar o interesse público como Valor-Notícia de Referência Universal, está-se afirmando que ele se constitui numa expectativa necessária da audiência, por um lado, e um atributo necessário da notícia, por outro. Podem ser apontadas três razões para isso: a) a informação jornalística se constitui em uma das mais importantes fontes de acesso ao direito à informação dos cidadãos (GENTILLI, 2005); b) ela contribui para a formação da agenda de temas sobre os quais os cidadãos irão discutir e formar suas próprias convicções em relação às mais diversas esferas da vida social (GOMES, 2004); e c) ela é potencialmente geradora de "impacto público", isto é, provoca consequências práticas na vida das pessoas, independentemente de elas serem ou não parte da audiência real de uma dada organização jornalística (GUERRA, 2008, p. 235).

A relação das organizações com suas audiências extrapola, em consequência, qualquer alegação de que os parâmetros de relevância se esgotem no âmbito de um contrato meramente privado entre produtores de conteúdo e receptores. A divulgação de notícias, além de constituir a oferta pública de informações a partir das quais os cidadãos orientam sua ação no mundo, pode provocar consequências na vida das pessoas independentemente da intenção do emissor ou da audiência para a qual se destina.
Assumindo-se, então, a verdade e a relevância (desdobrada nas duas ordens de valores-notícia) como parâmetros de qualidade jornalística, há que se considerar dois fatores importantes para o desempenho organizacional: a eficiência e a eficácia. Eficiência "significa 0 alcance de resultados com o mínimo de recursos" (CHIAVENAT0, 2007, p. 342). A eficiência mede o nível de satisfação interna da organização com relação aos custos do seu trabalho. No caso de uma organização jornalística, a eficiência será avaliada com base nas despesas e no esforço que a organização empenha para alcançar notícias que atendam aos parâmetros de qualidade considerados (verdade e relevância). Quanto mais próxima a organização estiver desses parâmetros, com um menor esforço de produção, maior será a sua eficiência.

A eficácia, por sua vez, é a medida do quanto a organização atinge seus objetivos. No nosso caso, o objetivo considerado é produzir notícias verdadeiras e relevantes para sua audiência. Segundo Chiavenato (2007, p. 342), "a eficácia analisa o lado da saída do sistema e trata da implementação dos objetivos: fazer o que se planejou. As medidas de eficácia devem refletir se os resultados desejados estão sendo atingidos". Ao produzir notícias verdadeiras e relevantes, a organização jornalística estaria sendo eficaz. Se as notícias produzidas contiverem erros e forem irrelevantes, poder-seia dizer que tal organização não estaria sendo eficaz na realização do seu trabalho. 
0 desafio de uma organização será, portanto, administrar a eficiência e a eficácia de seu processo de produção a fim de alcançar o melhor resultado jornalístico, isto é, oferecer um produto que contemple as expectativas da sociedade e de sua audiência. A eficiência gera ganhos de produtividade para a organização, o que é um tipo de recompensa buscado. A eficácia gera satisfação para a audiência, o que a motiva a continuar cliente da organização que atende as suas expectativas. A melhor relação entre eficiência e eficácia vai gerar a efetividade: "ser efetivo significa que o processo alcançou os objetivos propostos com uma utilização ótima de recursos" (JORNET, 2006, p. 28, tradução nossa).

A busca da efetividade na gestão da qualidade é essencial para a auto-sustentação da organização. Uma organização que comprometa mais recursos do que pode para alcançar a qualidade pretendida pode se tornar inviável, colocando em risco sua sobrevivência, os empregos que gera e os benefícios que oferece à própria sociedade. Assim, a busca da qualidade deve estar associada à utilização racional dos recursos disponíveis, a fim de aliar prestação de serviço de qualidade e responsabilidade social com auto-sustentabilidade.

\section{Sistema de Gestão da Qualidade em Jornalismo: diretrizes iniciais}

Qualquer modelo de gestão de qualidade em jornalismo deve conciliar, portanto, a busca pela qualidade em consonância com a efetividade de seu desempenho. Isso requer que a qualidade, como objetivo organizacional, perpasse toda a estrutura da organização, da alta direção até os colaboradores da base, e esteja presente em todas as ações, dos diversos setores da organização, que concorram para a obtenção de um produto final que satisfaça aos padrões previamente definidos. Assim, vamos retomar os três eixos básicos em torno dos quais está se propondo um modelo inicial de sistema de gestão da qualidade para organizações jornalísticas: os compromissos e a estrutura organizacional, os processos de produção e os produtos.

Em relação aos compromissos e à estrutura organizacional, o desafio é avaliar um conjunto de itens que avalizem as credenciais da organização para a prática do bom jornalismo. Nesse grupo, não são os parâmetros em si (verdade e relevância) que são avaliados, mas a capacidade presumida de a organização vir a alcançá-los. Isso implica considerar sete aspectos:

\section{a) condições ambientais objetivas da} organização para o exercício do jornalismo: essas condições podem ser externas e internas. Entre as condições ambientais externas, está a existência de um mercado forte capaz de gerar fontes diversificadas de receita, a fim de diminuir o risco de dependência econômica em relação a anunciantes mais fortes; também está a existência de um ambiente político e jurídico que assegure as liberdades fundamentais necessárias ao jornalismo; etc. A análise desses 
fatores permite uma avaliação de fundo sobre as oportunidades e riscos da organização para a boa prática da atividade. Entre as condições ambientais internas, está o nível de incorporação tecnológica, de capacitação e treinamento de seu quadro de pessoal, de recursos e equipamentos necessários às coberturas, etc. A análise desses fatores internos permite avaliar o potencial de realização da organização. Todos esses elementos devem ser de amplo e profundo domínio da organização, pois, apenas a partir de tal consciência ambiental, ela poderá planejar seu modo de atuação visando à qualidade de seus produtos jornalísticos.

\section{b) afirmação dos valores democráticos como} princípios de ação editorial: se 0 interesse público se constitui num Valor-Notícia de Referência Universal, é fundamental que a organização esteja comprometida com os princípios que estruturam a vida democrática e seja fiadora dos direitos e deveres pertinentes ao jornalismo para com a sociedade. Nesse sentido, a avaliação busca identificar a existência de uma política editorial na qual se documentem e se tornem públicos os compromissos organizacionais com tais princípios e valores.

\section{c) a disposição de seu corpo dirigente em} perseguir as melhores práticas jornalísticas:

além de incorporar os valores democráticos à ação editorial, torna-se essencial que 0 corpo dirigente, que exerce forte influência sobre toda a equipe da organização, esteja engajado na defesa e implementação desses princípios, garantindo tanto os meios necessários para seu cumprimento como mecanismos constantes de avaliação sobre sua correta execução.

\section{d) foco nas necessidades e expectativas da} sociedade e de sua audiência: a organização jornalística recebe da sociedade muitas garantias para seu livre funcionamento, em contrapartida é essencial que esteja sintonizada com suas demandas. Além disso, especificamente, a parte da sociedade que constitui sua audiência real possui peculiaridades que devem ser respeitadas e atendidas, sempre e na medida do possível que isso atenda a sua legítima demanda de informações sem pôr em risco ou ferir valores relacionados ao interesse público. A avaliação deste item busca analisar a preocupação e os meios da organização em monitorar e pesquisar as expectativas a que visa atender.

\section{e) definição clara e precisa de diretrizes} editoriais: a organização precisa documentar suas diretrizes editoriais, de forma clara e inequívoca, a fim de publicamente afirmar seus compromissos e, internamente, orientar adequadamente 0 trabalho da equipe de profissionais. A avaliação, nesse caso, deve identificar a existência de documentos e de procedimentos organizacionais que deem visibilidade a tais diretrizes.

\section{f) conceitos e especificações dos processos e} produtos: as definições das diretrizes devem ser detalhadas a fim de caracterizar com precisão os 
atributos requeridos para os produtos bem como os meios adequados de proceder para se obtê-los. Tais procedimentos são orientações essenciais a serem incorporadas na operação rotineira de produção, a fim de garantir uniformidade de ação da equipe e alinhamento com os valores máximos defendidos pela organização, além de oferecer parâmetros claros para a avaliação de qualidade e de desempenho. A avaliação aqui busca também identificar a existência dessas orientações, capazes de assegurar que os padrões de referência e qualidade possam ser compreendidos e aplicados por todos os integrantes da organização, de forma consistente.

\section{g) existência de mecanismos gerenciais} capazes tanto de implementar os processos de produção com efetividade quanto de manter um sistema de auto-avaliação contínua de suas práticas: a organização precisa prover os meios necessários à operação de produção jornalística, que incluam planos de trabalho definidos, com clareza de metas e responsabilidades; recursos materiais e humanos adequados bem como indicadores de desempenho e qualidade fidedignos, validados e de fácil entendimento. Em consequência, a organização precisa demonstrar ter uma sistemática de avaliação dos seus resultados editoriais, a fim de demonstrar que consegue atingir as expectativas a que se propõe.

Esse conjunto de sete elementos se apresenta, de modo genérico, como fundamental para sinalizar as condições que a organização requer para se credenciar à boa prática jornalística, como a motivação e o compromisso de suas lideranças, gestão do trabalho, recursos humanos e materiais adequados, entre outros. Uma organização que não demonstre reunir tais condições dificilmente conseguirá implementar efetivamente uma prática jornalística que conduza à excelência.

Em relação aos processos de produção, a avaliação deve analisar a consistência dos planos de produção em relação aos aspectos contidos no item compromissos e estrutura organizacional. Trata-se de avaliar se o conjunto manifesto de intenções no primeiro grupo de requisitos é executado de fato quando da realização dos processos de trabalho. São quatro aspectos a serem considerados:

\section{a) os níveis de eficiência e eficácia dos} processos de produção: a organização deve desenvolver procedimentos que conduzam aos compromissos e objetivos organizacionais de forma consistente. Os atributos dos produtos - como a verdade e a relevância - devem ser alvos dos processos e alcançados dentro da melhor relação possível entre custo e resultados atingidos. A avaliação deve considerar se 0 tempo e os recursos utilizados no trabalho de produção são compatíveis.

\section{b) ferramentas adequadas e ajustadas} aos processos: para alcançar os requisitos demandados para os produtos, a organização deve dispor de ferramentas (softwares, documentos, livros, equipamentos, etc.) adequadas e 
articuladas aos processos, a fim de evitar problemas e limitações que comprometam as metas de desempenho e qualidade. A avaliação analisa se há disponibilidade e adequação de tais ferramentas à sistemática de trabalho da equipe.

\section{c) procedimentos compatíveis com as} especificações: uma vez que a organização defina especificações para os produtos, os procedimentos de trabalho devem ser avaliados e, se necessários, redirecionados para tais especificações, a fim de ajustar-se ao conjunto do esforço organizacional. A avaliação deve verificar, então, se os procedimentos conduzem aos resultados esperados.

\section{d) pessoas adequadamente preparadas: para se} implementar os processos, definir procedimentos e atingir especificações, é necessário que as pessoas encarregadas de operacionalizar tais decisões estejam devidamente preparadas e motivadas para tal. A avaliação busca analisar se o quadro de pessoal recebeu e recebe treinamento para executar o processo dentro dos padrões desejados.

Por fim, em relação aos produtos, 0 objetivo é estabelecer um sistema de avaliação para aferir se 0 resultado produzido pelas organizações está em conformidade com as expectativas da sociedade e da audiência. Esses requisitos devem ser basicamente de duas naturezas: material, em relação às características físicas do produto; e conteúdo, em relação às informações disponibilizadas: a) requisitos materiais: estão relacionados aos atributos do produto, como características estéticas, de correção textual, de suporte tecnológico, de formato, etc. Esses requisitos estão diretamente associados à apresentação e disponibilização do produto à audiência. A avaliação deve analisar se a forma como o produto é apresentado e disponibilizado está adequada às expectativas que a organização visa atender.

b) requisitos de conteúdo: estão relacionados a três aspectos - verdade da informação, relevância e ética. No primeiro caso - verdade - avalia-se se a informação está sustentada em elementos factuais; no segundo, se a informação passa pelo crivo das necessidades e expectativas da sociedade e da audiência; no terceiro caso, se a informação respeitou os valores de conduta profissional e social, especificamente, relacionados aos valores democráticos, como a pluralidade. A avaliação compara, portanto, 0 que é noticiado com os critérios que validam e valorizam uma informação jornalisticamente.

Tanto as três categorias de requisitos quanto os vários aspectos relacionados no interior de cada uma representam um mapeamento bastante sintético do conjunto de elementos e nuances a serem necessariamente considerados numa avaliação de qualidade. Longe de querer esgotar 0 assunto, a relação apresentada tem intenção de sugerir possibilidades a serem exploradas e melhor compreendidas em futuros trabalhos de pesquisa. 


\section{Conclusão}

0 objetivo deste artigo foi apresentar resultados preliminares de um trabalho de pesquisa ainda em andamento. Do ponto de vista estrito da discussão sobre a qualidade, é importante perceber como o tema tem ganhado destaque e, mais importante, 0 esforço feito por agentes no sentido de mapear, a partir de critérios claros e objetivos, formas de avaliação de resultados para organizações jornalísticas.

Tal desafio passará, no âmbito dos estudos em jornalismo, com certeza, por um embate também do ponto de vista teórico, haja vista que valores consagrados por tais ferramentas - como 0 compromisso com a verdade e a relevância - são contestados por varias correntes acadêmicas do campo. $\mathrm{E}$ isso gera uma dificuldade adicional a esse desafio, haja vista que para funcionar, como acontece em outras áreas, os princípios e referências de qualidade devem ser objeto de amplo consenso pelos vários atores envolvidos.

De qualquer forma, tal problema no âmbito do jornalismo nos força a uma discussão sobre nossa capacidade teórica de gerar resultados para uma atividade que é profissional, e em consequência, requer formas de avaliar ganhos e perdas com as investigações acadêmicas que se voltam sobre ela. Nesse sentido, nos impele à produção de pesquisas aplicadas voltadas para a descoberta de padrões comuns de aferição do bom jornalismo, dos meios profissionais necessários e eficazes para se alcançá-los e da busca pela inovação, visando à melhoria contínua, etc.

Enfim, nos abre novos horizontes acadêmicos, a fim de nos renovar em relação aos problemas, às formas de abordagem e aos resultados que esperamos produzir com nossa atividade científica na área do jornalismo.

\section{Referências}

ASSOCIAÇÃO BRASILEIRA DE NORMAS TÉCNICAS. NBR ISO 9000:2005: Sistemas de Gestão da Qualidade Fundamentos e vocabulário. 2005.

\section{AGÊNCIA DE NOTÍCIAS DOS DIREITOS DA}

INFÂNCIA. A infância na mídia, ano 10, número 14. Brasília: ANDI-Instituto Ayrton Senna, 2005. Disponível em: <http://www.andi.org.br>. Acesso em: 31 mar. 2009.

BERTRAND, Claude-Jean. 0 arsenal da democracia: sistemas de responsabilização da mídia. Tradução: Maria Leonor Loureiro. Bauru: Edusc, 2002. 513 p.

CARVALHO, Marly Monteiro de. Histórico da gestão da qualidade. In: CARVALHO, Marly Monteiro de et al. Gestão da qualidade: teoria e casos. Rio de Janeiro: Elsevier, 2005.

CHALABY, Jean K. The invention of journalism. London: Macmillan Press, 1998. 212 p.

CHIAVENATO, Idalbeto. Administração: teoria, processo e prática. 4. ed. Rio de Janeiro: Elsevier, 2007.411p.

FUNDAÇÃO NACIONAL DA QUALIDADE. Cadernos de excelência: introdução ao modelo de excelência da gestão. São Paulo, 2008. (Série Cadernos de Excelência)

EC0, Umberto. Lector in fabula. Tradução: Attílio Cancian. São Paulo: Perspectiva, 2002. 219 p.

FRANCISCATO, Carlos. A fabricação do presente: como o jornalismo reformulou a experiência do 
tempo nas sociedades ocidentais. São Cristóvão: UFS; Aracaju: Fundação Oviêdo Teixeira, 2005. 274 p.

GENTILLI, Victor. Democracia de massas: jornalismo e cidadania. Porto Alegre: PUC-RS, 2005.

GOMES, Wilson. Transformações da política na era da comunicação de massa. São Paulo: Paulus, 2004.

GOMES, Wilson. Jornalismo, fatos e interesses: ensaios de teoria do jornalismo. Florianópolis: Posjor/ UFSC-Insular, 2009.

GUERRA, Josenildo Luiz. Monitoramento de cobertura e produção experimental monitorada: pesquisa aplicada voltada para a qualificação de produtos e processos jornalísticos. Pauta Geral, Florianópolis, $n$. 9, v. 1, p. 181-220, 2007.

\section{0 percurso interpretativo na produção da}

notícia: verdade e relevância como parâmetros de qualidade jornalística. São Cristóvão: UFS; Aracaju: Fundação Oviêdo Teixeira, 2008. 290 p.

JORNET, Carlos. Gestión periodística: herramientas para lograr um periodismo efectivo y de calidad. 1ed. Buenos Aires: Prometeo Libros, 2006.

McQUAIL, Denis. Audience analysis. London: Sage Publications, 1997. 166 p.

MEDITSCH, Eduardo. Crescer para os lados ou crescer para cima: o dilema histórico do campo acadêmico do Jornalismo. In: CONGRESSO BRASILEIRO DE CIÊNCIAS DA COMUNICAÇÃO, 22, 1999, Rio de Janeiro. Anais do XXII Congresso Brasileiro de Pesquisadores em Comunicação. Rio de Janeiro: Intercom, 1999. CD-ROM.

MOREIRA, Daniel Augusto; QUEIR0Z, Ana Carolina. Inovação: conceitos fundamentais. In.: (orgS.). Inovação organizacional e tecnológica. São Paulo: Thomson Learning, 2007. p. 1-22.

PROPUESTA de indicadores para un periodismo de calidad. México: Universidad Iberoamericana, 2006. Disponível em: <http:// prende.masimagen.com.mx/images/stories/file/

librodigitalpropuestaindicadoresperiodismo calidadmexico.pdf>. Acesso em: 27 jun. 2009.

\section{INTERNATIONAL STANDARTIZATION \&} ACCREDITATION SERVICES. Quality management systems: guidelines for the implementation of international standards ISAS BC-9001:2003 and ISAS P-9001:2005 in broadcasting companies, Internet content producers and the press. Nova York, 2007. Disponível em: <www.isasgroup.com>. Acesso em: 28 mar. 2009.

PINTO, Manuel, MARINHO, Sandra. A qualidade em Jornalismo: problematização e operacionalização do conceito. Comunicação apresentada no I CONGRESSO LUSO-BRASILEIRO DE ESTUDOS JORNALÍSTICOS, 1.; CONGRESSO LUSO-GALEGO DE ESTUDOS JORNALÍSTICOS, 2., 2003, Porto.

Anais... Porto: Universidade Fernando Pessoa, 2003.. Disponível em: <http://repositorium.sdum.uminho.pt/ handle/1822/997>. Acesso em 01 de fevereiro de 2009.

SLACK, Nigel; CHAMBERS, Stuart; JOHNSTON, Robert. Administração da produção. 2. ed. Tradução: Maria Teresa Corrêa de Oliveira e Fábio Alher. Revisão Técnica: Henrique Luiz Corrêa. São Paulo: Atlhas, 2007. 747 p.

STAL, Eva. Inovação tecnológica, sistemas nacionais de inovação e estímulos governamentais à inovação. In.: MOREIRA, Daniel Augusto; QUEIR0Z, Ana Carolina (orgs.). Inovação organizacional e tecnológica. São Paulo: Thomson Learning, 2007. p. 23-53.

TRAQUINA, Nelson. 0 estudo do jornalismo no século XX. São Leopoldo: Unisinos, 2001. 
Sistema de Gestión de la Calidad aplicado al periodismo: posibilidades y directrices

\section{Resumen:}

Este artículo reflexiona sobre las posibilidades de desarrollar un sistema de gestión y evaluación de calidad para las organizaciones periodísticas. Analiza dificultades como la falta de métodos objetivos para medir las características de los productos y la falta de consenso sobre los valores y requisitos deseables. En él se apuntan desafíos: construir métodos fiables para obtener los valores de consenso y generar la innovación necesaria de los productos y procesos derivados de las evaluaciones. Se propone definir un concepto de calidad con dos requisitos básicos: verdad y relevancia. El artículo concluye con la presentación de una proposta preliminar del sistema de gestión de la calidad, fundamentada en tres partes: a) los compromisos y la estructura organizativa; b) los procesos de producción; y c) los productos.

\section{Palabras clave:}

Periodismo. Calidad. Innovación.

\section{System Quality Management applied to journalism: possibilities and guidelines}

\section{Abstract:}

The paper is about the possibilities of developing a management system and quality assessment for news organizations. It analyzes problems such as lack of objective methods for measuring the characteristics of products and the lack of consensus about the values and desirable requirements. It highlights the challenges: building reliable methods to obtain consensual values and the generation of innovation to products and processes that arise from the taken evaluations. It defines the concept of quality and proposes two basic requirements, truth and relevance. It concludes with the presentation of a preliminary proposal of system quality management in three parts: a) commitments and organizational structure; b) production processes; and c) products.

\section{Keywords:}

Journalism. Quality. Innovation. 


\section{Expediente}

A revista E-Compós é a publicação científica em formato eletrônico da Associação Nacional dos Programas de Pós-Graduação em Comunicação (Compós). Lançada em 2004, tem como principal finalidade difundir a produção acadêmica de pesquisadores da área de Comunicação, inseridos em instituições do Brasil e do exterior.
E-COMPÓS I www.e-compos.org.br I E-ISSN 1808-2599

Revista da Associação Nacional dos Programas de Pós-Graduação em Comunicação. Brasília, v.13, n.3, set./dez. 2010.

A identificação das edições, a partir de 2008 passa a ser volume anual com três números.

\section{CONSELHO EDITORIAL}

Afonso Albuquerque

Universidade Federal Fluminense, Brasil

Alberto Carlos Augusto Klein

Universidade Estadual de Londrina, Brasi

Alex Fernando Teixeira Primo

Universidade Federal do Rio Grande do Sul, Brasil

Alfredo Vizeu

Universidade Federal de Pernambuco, Brasi

Ana Carolina Damboriarena Escosteguy

Pontifícia Universidade Católica do Rio Grande do Sul, Brasil

Ana Silvia Lopes Davi Médola

Universidade Estadual Paulista, Brasil

André Luiz Martins Lemos

Universidade Federal da Bahia, Brasil

Ângela Freire Prysthon

Universidade Federal de Pernambuco, Brasil

Antônio Fausto Neto

Universidade do Vale do Rio dos Sinos, Brasil

Antonio Carlos Hohlfeldt

Pontifícia Universidade Católica do Rio Grande do Sul, Brasil

Arlindo Ribeiro Machado

Universidade de São Paulo, Brasil

César Geraldo Guimarães

Universidade Federal de Minas Gerais, Brasil

Cristiane Freitas Gutfreind

Pontifícia Universidade Católica do Rio Grande do Sul, Brasil

Denilson Lopes

Universidade Federal do Rio de Janeiro, Brasil

Eduardo Peñuela Cañizal

Universidade Paulista, Brasil

Erick Felinto de Oliveira

Universidade do Estado do Rio de Janeiro, Brasil

Francisco Menezes Martins

Universidade Tuiuti do Paraná, Brasil

Gelson Santana

Universidade Anhembi/Morumbi, Brasil

Goiamérico Felício

Universidade Federal de Goiás, Brasil

Hector Ospina

Universidad de Manizales, Colômbia

Herom Vargas

Universidade Municipal de São Caetano do Sul, Brasil

leda Tucherman

Universidade Federal do Rio de Janeiro, Brasil

Itania Maria Mota Gomes

Universidade Federal da Bahia, Brasil

Janice Caiafa

Universidade Federal do Rio de Janeiro, Brasil

Jeder Silveira Janotti Junior

Universidade Federal da Bahia, Brasil

\section{João Freire Filho}

Universidade Federal do Rio de Janeiro, Brasil

John DH Downing

University of Texas at Austin, Estados Unidos

José Luiz Aidar Prado

Pontifícia Universidade Católica de São Paulo, Brasil

José Luiz Warren Jardim Gomes Braga

Universidade do Vale do Rio dos Sinos, Brasi

Juremir Machado da Silva

Pontifícia Universidade Católica do Rio Grande do Sul, Brasil

Lorraine Leu

University of Bristol, Grã-Bretanha

Luiz Claudio Martino

Universidade de Brasília, Brasil

Maria Immacolata Vassallo de Lopes

Universidade de São Paulo, Brasil

Maria Lucia Santaella

Pontifícia Universidade Católica de São Paulo, Brasil

Mauro Pereira Porto

Tulane University, Estados Unidos

Muniz Sodre de Araujo Cabral

Universidade Federal do Rio de Janeiro, Brasil

Nilda Aparecida Jacks

Universidade Federal do Rio Grande do Sul, Brasil

Paulo Roberto Gibaldi Vaz

Universidade Federal do Rio de Janeiro, Brasil

Renato Cordeiro Gomes

Pontifícia Universidade Católica do Rio de Janeiro, Brasil

Ronaldo George Helal

Universidade do Estado do Rio de Janeiro, Brasil

Rosana de Lima Soares

Universidade de São Paulo, Brasil

Rossana Reguillo

Instituto Tecnológico y de Estudios Superiores do Occidente, México

Rousiley Celi Moreira Maia

Universidade Federal de Minas Gerais, Brasil

Samuel Paiva

Universidade Federal de São Carlos, Brasil

Sebastião Albano

Universidade Federal do Rio Grande do Norte, Brasil

Sebastião Carlos de Morais Squirra

Universidade Metodista de São Paulo, Brasil

Simone Maria Andrade Pereira de Sá

Universidade Federal Fluminense, Brasi

Suzete Venturelli

Universidade de Brasília, Brasil

Valério Cruz Brittos

Universidade do Vale do Rio dos Sinos, Brasil

Veneza Mayora Ronsini

Universidade Federal de Santa Maria, Brasil

Vera Regina Veiga França

Universidade Federal de Minas Gerais, Brasil

\section{COMISSÃO EDITORIAL}

Felipe da Costa Trotta I Universidade Federal de Pernambuco, Brasi Rose Melo Rocha I Escola Superior de Propaganda e Marketing, Brasil Adriana Braga I Pontifícia Universidade Católica do Rio de Janeiro, Brasil

\section{CONSULTORES AD HOC}

Virginia Pradelina da Silveira Fonseca I Universidade Federal do Rio Grande do Norte, Brasi Christa Liselote Berger I Universidade do Vale do Rio dos Sinos, Brasi Márcia Benetti I Universidade Federal do Rio Grande do Sul, Brasil Tattiana Gonçalves Teixeira I Universidade Federal de Santa Catarina, Brasil

Gislene da Silva I Universidade Federal de Santa Catarina, Brasil José Afonso Junior I Universidade Federal de Pernambuco, Brasil EDIÇÃO DE TEXTO E RESUMOS I Everton Cardoso

TRADUÇÕES PARA O INGLÊS I Sieni Campos, Lisa Earl Castillo e Sabrina Glendhill EDITORAÇ̃̃ ELETRÔNICA I Roka Estúdio
COMPOS I wWw.compos.org.br

Associação Nacional dos Programas de Pós-Graduação em Comunicação

Presidente

Itania Maria Mota Gomes

Universidade Federal da Bahia, Brasil

itania@ufba.br

Vice-presidente

Julio Pinto

Pontifícia Universidade Católica de Minas Gerais, Brasil juliopinto@pucminas.br

Secretária-Geral

Ana Carolina Escosteguy

Pontifícia Universidade Católica do Rio Grande do Sul, Brasil carolad@pucrs.br 